\title{
The algesic syndrome in spinal cord trauma
}

\author{
A V Livshits \\ Professor and Director, All Union Centre of Spinal Cord Trauma, Bolshevistokay Str.15, \\ Moscow, CIS.
}

This article represents the author's experience in the diagnosis and management of pain in patients with spinal cord injuries, and describes methods applied to objectively evaluate pain syndromes and different surgical procedures to alleviate such pain. Instrumental methods for pain relief are also briefly discussed.

Key words: spinal cord injury; algesic syndrome; evoked potentials; hypothermia; DREZ lesions; cordotomy; commissurotomy.

\section{Introduction}

There are many scientific explanations for pain following spinal cord injury, but the problem of pain is extremely complex, concerning cause, mechanisms, and a structural basis.

We use special evoked potential (EP) studies to evaluate some therapies for the alleviation of pain. The difficulties of understanding pain problems are due to the absence of objective criteria.

We describe EP in relation to electrical stimulation of the forearm skin, and registered the inhibition of these evoked potentials under effective percutaneous analgesic electrical stimulation. We also used EP to evaluate chronic algesic syndromes and the effect of analgesic electrical stimulation of the posterior columns of the spinal cord. Before the employment of analgesic electrical stimulation of the posterior columns in those with a severe algesic syndrome, study of the somatosensory cortex in response to electrical skin stimulation revealed high amplitude $(15 \mathrm{mcv})$ slow positive oscillation with a latent peak period of 220 msec mainly at point $\mathrm{Co}$, whereas it was virtually absent at point $\mathrm{C} 3$.

A sharp reduction of this potential (to $5 \mathrm{mcv}$ ) has been registered after analgesic electrical stimulation when pain virtually disappeared. Pain appeared once again after a temporary termination of the analgesic electrical stimulation and, at the same time, positive oscillation at point Co with a peak period of $220 \mathrm{msec}$ and the amplitude of
$14 \mathrm{mcv}$ has once again appeared with the registration of somatosensory EP (Fig 1).

A clearly pronounced high amplitude $(12-15 \mathrm{mcv})$ positive oscillation with a latent peak period of $240 \mathrm{msec}$ was noted if there was ineffective analgesic stimulation

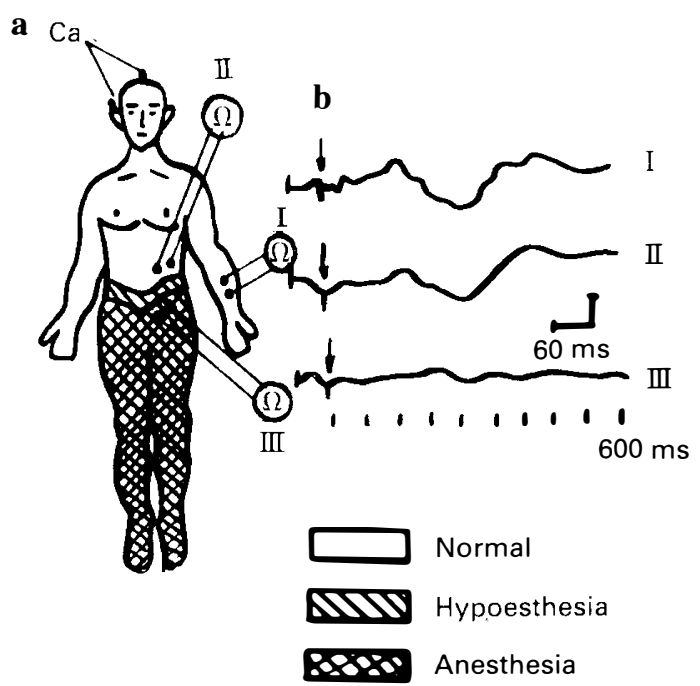

Figure 1 Use of nociceptive stimulation to define the boundaries of normal and abnormal sensitivity in a patient with spinal cord damage at T12 level. (a) Location of stimulating electrodes (Co, recording from the cortex). (b) Somatosensory evoked potentials in response to painful stimulation: I, at the forearm (stimulation of the median nerve); II, in the zone of normal sensitivity; III, in the zone of anesthesia (recording from the vertex area only). The zone of hypoesthesia is indicated by small dots. 
of the posterior columns. In our series a slow potential, related to algesic afferentation, reached its maximal value not in the somatosensory zone of the cortex (which corresponds to point $\mathrm{C} 3$ ), but at point $\mathrm{Co}$, which corresponds to the vertex zone, and which, according to modern concepts, is the projection zone to the cortex of large nonspecific structures.

We may assume that the inhibition of the somatosensory EP 240 component by analgesic electrical stimulation may point to the relationship of this component to the algesic syndrome.

\section{Thermography}

Another objective tool which assists in the diagnosis of pain syndromes is thermography which, in conjunction with the clinical findings, permits accurate delineation of the painful area. ${ }^{1,2}$

\section{Treatment}

\section{Hypothermia}

Our studies have shown ${ }^{3}$ that the meningeal responses to the hypothermic procedure are mainly due, not to the cooling as such, but rather to the pressure exerted by the cooling fluid on the brain and spinal cord as well as on the meninges. Local hypothermia was performed in 70 patients with spinal cord injuries. The first group consisted of 32 patients with cervical injuries, the second group of 38 patients with thoracic injuries (Table I).

It was noted that hypothermia was more effective in patients with injuries at the thoracic level, and that satisfactory results were achieved in $52 \%$ of cases.

As a complication, meaningful irritation lasting several days was noted.

\section{Surgical procedures}

Surgical relief of pain should be considered when conservative methods of treatment are ineffective.

\section{Dorsal root entry zone (DREZ) lesions}

Traumatic injury to the brachial plexus can result in a well known severe pain syndrome which involves the neck, the humero-scapular region, and the arm. The pain, often burning in quality, not infrequently resembles phantom limb pain. The DREZ operation consists in destruction of the entry zone of posterior roots by means of electrocoagulation with the employment of a special electrode. Following the operation, transient motor and sensory disturbances in the homolateral lower limb occur in approximately $45 \%$ of cases. We have carried out 21 operations (Table II).

A good result, that is the complete disappearance of pain, was achieved in $62 \%$ of cases.

\section{Cordotomy}

Indications for cordotomy are for patients with very severe pain affecting one half of the body, bilateral pelvic or pelvic and sacral pain, or pain localised in one extremity. The operation consists of performing a laminectomy at C7-T4 levels with hemisection of the antero-lateral spinothalamic tract in the T3-T4 segments. We have perfomed 80 cardotomies at the T3 -4 segments, with over 1-2 years of observation. A good result was only obtained in $23 \%$ (Table III). Complications of cordotomy that may occur were:- dysfunction of pelvic organs, paresis of the lower limbs, and recalcitrant painful dysesthesiae below the cordotomy level. The recurrence of painful sensations, particularly after a high cervical cordotomy is attributable to the complexity and diversity of pain transmission pathways.

Table I The effect of hypothermia

\begin{tabular}{lccc}
\hline Level of injury & Satisfactory effect & No effect & Total \\
\hline Cervical & 7 & 25 & 32 \\
Thoracic & 30 & 8 & 38 \\
Total & 37 & 33 & 70 \\
\hline
\end{tabular}


Table II DREZ operations

\begin{tabular}{lccccc}
\hline $\begin{array}{l}\text { Level of } \\
\text { injury }\end{array}$ & $\begin{array}{c}\text { Level of } \\
\text { surgery }\end{array}$ & $\begin{array}{c}\text { Good } \\
\text { result }\end{array}$ & $\begin{array}{c}\text { Satisfactory } \\
\text { result }\end{array}$ & No effect & Total \\
\hline C5-6 & C8-T1 & 3 & 3 & - & 6 \\
T11-L1 & L1-2 & 10 & 5 & - & 15 \\
Total & & 13 & 8 & 21 \\
\hline
\end{tabular}

Table III Cordotomy

\begin{tabular}{lccccc}
\hline $\begin{array}{l}\text { Level of } \\
\text { injury }\end{array}$ & $\begin{array}{c}\text { Level of } \\
\text { surgery }\end{array}$ & $\begin{array}{c}\text { Good } \\
\text { result }\end{array}$ & $\begin{array}{c}\text { Satisfactory } \\
\text { result }\end{array}$ & No effect & Total \\
\hline T5-8 & T3-4 & 8 & - & 17 & 25 \\
T10-12 & T3-4 & 7 & -1 & 16 & 35 \\
T12-L1 & T3-4 & 4 & 1 & 60 & 80 \\
Total & & 19 & & & \\
\hline
\end{tabular}

\section{Commissurotomy (commissural myelotomy)}

Commissurotomy is performed for the management of bilateral pain syndromes, particularly visceralgia, resistant to drug treatment.

Livshits ${ }^{4}$ has described the results of cervical and thoracolumbar commissurotomies in 23 patients with a severe pain syndrome consequent to spinal cord injury in 21 patients, and to inflammation of the spinal meninges in the 2 others. Eightyseven per cent of the patients enjoyed good relief of pain when followed up for up to 10 years (Table IV).

Postoperative complications included reduced intestinal motor function, which could be improved by drugs, and impaired pelvic organ functions because of damage to the spinal cord at operation. Postcommissurotomy histological studies revealed bilat- eral ascending degeneration of the spinothalamic tract and, in a number of patients, degenerative changes in the dorsal horns of the spinal cord due to direct injury during dissection of the commissures. But the rather marked morphological alterations in cord structure were not necessarily manifested by distinct neurological disturbances, which attests to considerable compensatory potentials of the nervous system.

\section{Dorsal column stimulation (DCS)}

The possibility of treating pain by electrical stimulation of the dorsal columns of the spinal cord was suggested by Melzack and Wall ${ }^{5}$ on the basis of their gate control theory of pain and in the belief that in these columns are the B fibres which are responsible for pain transmission and can be stimulated selectively.

The prime indication for DCS is chronic

Table IV Commissural myelotomy

\begin{tabular}{lccccc}
\hline $\begin{array}{l}\text { Level of } \\
\text { injury }\end{array}$ & $\begin{array}{c}\text { Level of } \\
\text { surgery }\end{array}$ & $\begin{array}{c}\text { Good } \\
\text { result }\end{array}$ & $\begin{array}{c}\text { Satisfactory } \\
\text { result }\end{array}$ & No effect & Total \\
\hline C5-6 & T6-10 & 3 & - & - & 3 \\
T11-L1 & T6-10 & 17 & 3 & - & 20 \\
Total & & 20 & 3 & 23 \\
\hline
\end{tabular}


pain lasting at least 2 months and resistant to any of the therapies that can cure the underlying disease; moreover, the patient should be refractory to all analgesics and be unable to become habituated to the pain. These criteria are met by phantom limb pain following spinal cord damage, or injury to the brachial or lumbar plexuses; pain after failed surgery for intervertebral disc herniation; causalgia; pain due to peripheral vascular disease; sensory neural pain associated with damage to nerve trunks; arthralgia; and arachnoidal pain.

In the USSR, the first radiofrequencypowered spinal cord stimulator, consisting of an external transmitter with antennae and an implantable receiver with electrodes, was designed in our centre in collaboration with outside engineers (Fig 2).

The output parameters of the stimulating current pulses can be adjusted over wide ranges (frequency from 15 to 150 per second, duration from 0.1 to $1.4 \mathrm{msec}$, and amplitude from 0.5 to $10 \mathrm{~V}$ at a load of 500 ohms). The stimulator has a switch for selection of 9 available operating modes

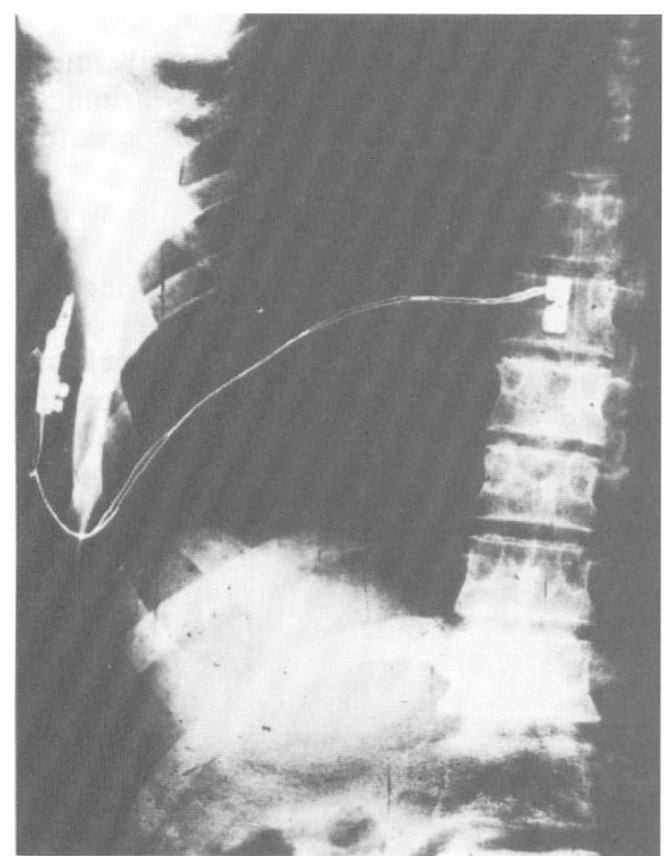

Figure 2 Anteroposterior roentgenogram in a patient with an implanted dorsal column stimulator. (using a monopolar positive pulse, a monopolar negative pulse, a bipolar pulse, or any of their 6 different combinations).

Electrodes are introduced into the epidural space via special needles with a curved tip. The electrodes and radiofrequency receiver are implanted under local anesthesia with the patient lying prone. A curved-tip needle is passed into the epidural space, which can be recognised by the ease with which physiological saline can be injected through the needle. The generator transforms signals into electric pulses of appropriate parameters and transmits them to the spinal cord. The parameter ranges are as follows: frequency, $10-100 \mathrm{~Hz}$; pulse width, 0.7-3.0 msec; current intensity, $0.8-$ $8.5 \mathrm{~mA}$. Stimulation can be discontinued by applying a magnet to the skin over the generator site (Fig 3).

The results and problems of DCS have been discussed in a number of publications. In general, the best results are obtained in patients with chronic back pain after unsuccessful operations for osteochondrosis, or for discogenic disease, and for those with
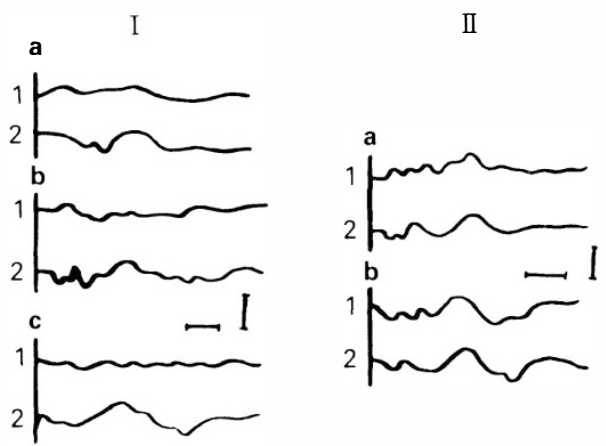

Figure 3 Somatosensory evoked potentials on antinociceptive electrostimulation of dorsal columns in patients with pain syndrome. I. Patient on whom the stimulation was effective: (a) before stimulation; (b) good pain relieving effect, with a reduction of the P220 pack peak to $7 \mathrm{mcv}$; (c) potentials recorded at 3 hours after discontinuation of stimulation when pain recurred. II. Patient in whom the stimulation was ineffective: (a) before stimulation; (b) after electrode implantation pain persisted and the P240 peak remained large $(15 \mathrm{mcv}) .1$ and 2 are individual measurements. 
deafferentation pain. In contrast, DCS has little benefit for patients with thalamic pain or phantom limb pain. Our observations show that up to $56 \%$ of our patients with spinal cord trauma (75 patients) had a good and satisfactory effect from DCS.

\section{Conclusions}

The problem of pain relief in patients with spinal cord injuries cannot be considered to be resolved. The effect of treatment depends to a great extent on the precise diagnosis of the algesic syndrome mechanism as well as on the correct choice of methods of treatment (Fig 4). It would be unwise and difficult to rely on a universal method of algesic syndrome therapy.

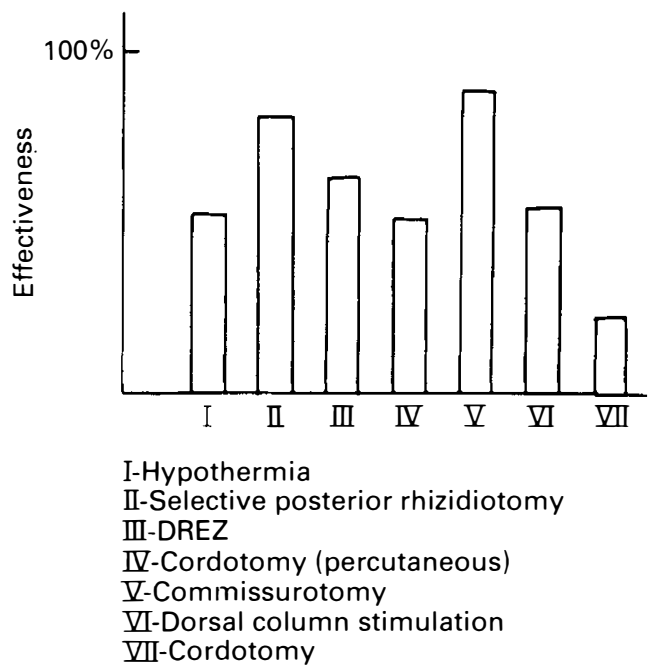

Figure 4 The results of analgesic operations.

\section{References}

1 Wexler CE (1983) Atlas of Thermographic Lumbar Patterns. Thermographic Servicer Inc, Encino, California.

2 LeRoy PL, Bruner WM, Christian CR, Filasky R, LeRoy S (1985) Thermography as a diagnostic aid in the management of chronic pain. In: Aronoff GM, editor Evaluation and Treatment of Chronic Pain. Urban \& Schwarzenberg, Baltimore-Munich: 231-250.

3 Livshits AV, Ufimtsev PP (1982) Hypothermy of the spinal cord in spasticity. Vopr Neirochir 4: 43-47. (In Russian).

4 Livshits AV (1986) Functional microneurosurgery of the spinal cord. In: Kohovalov AN, Livshits AV, editors. Neirokhirurgicheskay Patologiya Spinnogo Mozga (Neurosurgical Pathology of the spinal Cord). Meditsina, Moscow: 8-17. (In Russian).

5 Melzack R, Wall PD (1965) Pain mechanisms. A new theory. Science 150: 971-979. 